\title{
Systematic Study to Convert Polyvinyl Chloride Waste into Commercial Chemicals
}

\author{
Abduel Majid K. Najjar, Mohamed A. Elmelah, Rashid S. R. Ltayef, and Fahima N. Abudher
}

\begin{abstract}
Polyvinyl chloride (PVC) waste is considered one of the environmentally hazardous plastic materials accumulating in huge quantities in landfills. This work was conducted for the purpose of using green chemistry techniques to convert the PVC waste into other chemicals that could be used for commercial purposes. Pyrolysis process of the PVC waste was carried out under inert atmospheric condition. The effect of grain size, temperature and heating time on the amount of evolved hydrogen chloride gas $(\mathrm{HCl})$ was investigated. More than $95 \%$ of theoretical calculated amount of $\mathrm{HCl}$ was evolved before any emission of any other organic fumes. The evolved $\mathrm{HCl}$ was trapped and converted into concentrated hydrochloric acid $(11.22 \mathrm{M})$ and then to a highly pure sodium chloride salt. The residual black material was heated further to remove and trap oily organic fumes. About $14 \%$ of initial PVC weight was found to be as heavy metals free oil and may be used as fuel. Finally, 27.74\% of the degraded PVC remained as carbon black. The carbon black was grounded and acid digested to remove and determine heavy metal ions content.
\end{abstract}

Index Terms-PVC waste, pyrolysis process, thermal degradation, organic fumes, black carbon.

\section{INTRODUCTION}

Waste in general, is an inevitable byproduct of all human development and culture activities, and is directly proportional to the consumption of resources. Population and economic growth not only lead to increase in volume of waste but also to great changes in its specification and contents. There is tremendous increase in some nonbiodegradable contents, particularly plastic waste, which contain polyvinyl chloride (PVC). PVC waste has attracted great attention because cannot be decomposed in nature and hence its safe disposal is creating extraordinary technical, health, environmental, economic, political and social problems [1]. PVC is one of the most widely accumulated plastic materials in landfills after end-life uses and became an active area of scientific research for the objective of creating a proper Solid Waste Management System. The methods and the technologies of recycling of PVC waste have been reviewed [2], [3]. It seems that the recycling of PVC waste into new items and reducing the waste accumulation is still

Manuscript received March 19, 2014; revised May 22, 2014.

Abduel Majid K. Najjar is with the Department of Chemical Engineering, Faculty of Engineering (Al-Garaboli), Al-Mergeb University, Al-Mergeb, Libya (e-mail: abduelmajid60@yahoo.com).

Mohamed A. Elmelah and Fahima N. Abudher are with the Chemistry Department, Faculty of Science, University of Tripoli, P.O. Box 82849 Tripoli, Libya.

Rashid S. R. Ltayef is with the Department of Environmental Science and Engineering, Libya Academy of Higher Studies, P. O. Box 72331 Zanzur, Libya. very limited. Thermal degradation of PVC waste and its conversion into other commercial chemicals could be the best technical solution.

Many works have been reported on the pyrolysis process and kinetics of PVC waste pyrolysis at different temperatures and heating rates [4]-[8]. Saeed and his coworkers studied slow pyrolysis of PVC in fluidized bed reactor at different temperatures [9]. They found that the release of most of chlorine and other organic compounds was dependent on heating temperature. In the PVC matrix, the $\mathrm{C}-\mathrm{Cl}$ bonds in the structure have a relatively lower binding energy than both the C-C and C-H bonds [10], [11]. This fact proves that the bonds of chlorine with carbon atom in the PVC chains are broken first lead to dichlorination in the first stages of the thermal degradation. Generally, PVC material is characterized by having a very poor thermal conductivity. In the first stages of thermal degradation of large PVC particles, the release of chlorine followed by thermal crosslinking of the outer surface layer may forbid the further dechlorination at the same temperature and the formation of organic vapors. The thermal degradation of small sized PVC particles may lead to fast release of $\mathrm{HCl}$ gas at a particular temperature. In order to maintain fast release of $\mathrm{HCl}$ gas and eliminate the emission of the organic compounds resulted from the thermal degradation of PVC waste, optimized the experimental conditions are extremely needed. This work aims to study the effects of PVC waste particle size, heating temperature and heating time on the quantitative liberation of pure $\mathrm{HCl}$ before any emission of organics, prepare $\mathrm{HCl}$ solution and harvesting residual carbon black under controlled experimental conditions. It is known that PVC degrades at relative high temperature producing hydrogen chloride and polyene chains, followed by thermal crosslinking and then initiation of the polymer chain scissions. To avoid any reaction with oxygen, the dehydrochlorination process was carried out under nitrogen atmospheric condition.

\section{MATERIALS AND METHODS}

\section{A. Materials}

Samples used in this work were PVC waste collected from National Company for manufacturing of Plastic pipes located in Janzur west of Tripoli-Libya. The PVC waste were washed with tap and distilled water to remove any sand and dirt, oven dried at $60{ }^{\circ} \mathrm{C}$, grounded to $0.5-4.0 \mathrm{~mm}$ particle sizes using FBM 8000W DIS20402068 grinder and then sieved to specific particle size.

\section{B. Thermal Decomposition of PVC Waste}

A closed glass setup consisted of three necked round 
bottomed flask fitted with a condenser connected to three parallel trap flasks, thermometer, inert gas supplied (nitrogen of $99.60 \%$ purity) at $100 \mathrm{ml} / \mathrm{min}$ flow rate and thermostatic heating mantel is assembled. Two trap flasks filled with toluene for organic vapors and $\mathrm{NaOH}$ solution or $\mathrm{H}_{2} \mathrm{O}$ for $\mathrm{HCl}$ gas. The setup was preheated to $200{ }^{\circ} \mathrm{C}$ prior to introduction of PVC waste sample $(5.0 \mathrm{~g})$ into the flask and the heating continued under nitrogen atmosphere for a defined period of time. Several experimental parameters of the process were investigated to determine the optimum conditions. The effects of heating temperature, heating time and particle size of PVC waste on the emitted vapors are studied. Set of experiments are carried out by changing the temperature $\left(200,250,275,300\right.$ and $\left.325^{\circ} \mathrm{C}\right)$ and heating times $(7.5$ to $60 \mathrm{~min})$ at each temperature. The amount of hydrogen chloride $(\mathrm{HCl})$ gas evolved at each temperature is trapped in $0.3 \mathrm{M}$ sodium hydroxide solution and measured by titrating against $0.2 \mathrm{M} \mathrm{HCl}$ solution.

PVC waste granules are grounded further to grain sizes of $0.5,1.0$, and $2.0 \mathrm{~mm}$ and sieved out in order to study the effect of particle size. Exactly $5.0 \mathrm{~g}$ of each grain size was pyrolysis at optimum temperature to release of the maximum amount of $\mathrm{HCl}$ before organic fumes liberated. The amount of $\mathrm{HCl}$ evolved was calculated and heating time before organic fumes liberation was recorded for each experiment.

\section{Collection of $\mathrm{HCl}$}

These experiments were conducted by using the most determined previously suitable conditions for PVC pyrolysis (optimum temperature, heating time and grain size). The experiment was repeated using the two $\mathrm{HCl}$ traps in sequence, the first contained $100 \mathrm{ml}$ and the second $500 \mathrm{ml}$ distilled water. The experiment was repeated several times until the first trap was saturated with $\mathrm{HCl}$. The $\mathrm{HCl}$ concentration in the two traps was determined after the degradation of $100.0 \mathrm{~g}$ PVC samples (each sample $10.0 \mathrm{~g}$ ). A sample of $\mathrm{HCl}$ solution is used to determine its concentration by titration method against $0.4 \mathrm{M} \quad \mathrm{NaOH}$ using phenolphthalein indicator.

The experiment was repeated to investigate the purity of the collected $\mathrm{HCl}$. The $\mathrm{HCl}$ trap contained an equivalent amount of $\mathrm{NaOH}$ solution $(500 \mathrm{ml})$ reacted the emitted $\mathrm{HCl}$ from $15.0 \mathrm{~g}$ PVC waste. The final solution was transferred to a $1000 \mathrm{ml}$ beaker and evaporated to dryness. Finally, the purity of the produced salt was analyzed by using CHNS elemental analyzer (Euro Ea Elemental Analyzer).

\section{Extraction and Collection of Organic Materials}

These experiments were performed on the black solid material remained after $\mathrm{HCl}$ evolution for the purpose of converting it into carbon black. The pyrolysis setup was assembled with collection flask to collect the produced organic materials. In this process, the temperature was raised to $400{ }^{\circ} \mathrm{C}$ for $2.0 \mathrm{hr}$ during which all the organic material was formed and evaporated, Amount of evolved organics and black carbon remains were determined by weighting of starting and final solid materials.

\section{E. Extraction of Black Carbon and Organic Metals Content}

Heavy metal compounds are normally used as additives in manufacturing process of PVC pipes as coloring agent. Therefore, the carbon black from pyrolysis process must contain heavy metal ions. These metals may be removed to have a clean black carbon as end product. To remove the ions, a sample of black carbon was grounded to fine particle sizes using a Ball Miller. About $20 \mathrm{ml}$ of concentrated nitric acid was added to a $1.0 \mathrm{~g}$ sample in a glass beaker and the mixture heated to near dryness. This step repeated twice, distilled water was then added and the mixture filtered into a $50.0 \mathrm{ml}$ volumetric flask. The volume completed to the mark and concentration of $\mathrm{Zn}, \mathrm{Cu}, \mathrm{Pb}, \mathrm{Cd}, \mathrm{Co}$ and $\mathrm{Fe}$ were determined using Atomic Absorption Spectrophotometer (Alpha 4 Atomic Absorption Spectrophotometer).

A sample of PVC resin was pyrolysis in the same way as the PVC waste. Exactly, $1.0 \mathrm{~g}$ carbon black from this sample was grounded, $\mathrm{HNO}_{3}$ digested and the heavy metal content was determined and used as a reference sample.

The presence of heavy metal ions in the organic distillate was also investigated by treating $0.5 \mathrm{~g}$ sample by $10.0 \mathrm{ml}$ concentrated $\mathrm{HNO}_{3}$ in a beaker and heated to near dryness. After that, $5.0 \mathrm{ml}$ of hydrogen peroxide $\left(\mathrm{H}_{2} \mathrm{O}_{2}\right)$ was added and the mixture boiled for $3 \mathrm{~min}$. The final mixture was filtered into $50.0 \mathrm{ml}$ volumetric flask and the heavy metals content was also measured.

\section{RESULTS AND DISCUSSION}

Hydrogen chloride is one of the main degradation products in the pyrolysis process of polyvinyl chloride. The presence of air in the process leads to the formation of carbon monoxide and carbon dioxide beside other organic products. To collect hydrogen chloride and maintain high yield of carbon black, a set of thermal degradation experiments were performed to PVC under inert atmosphere at different temperatures ranged from $200{ }^{\circ} \mathrm{C}$ to $325{ }^{\circ} \mathrm{C}$ for various time intervals for each processing temperature. Figure 1 shows the dehydrochlorination of PVC at various temperatures as a function of heating time. It can be seen that the percentage of the emitted $\mathrm{HCl}$ increases when the PVC particles heated at $200{ }^{\circ} \mathrm{C}$ up to $45 \mathrm{~min}$ at constant temperature. Only about $23 \%$ of the theoretical pre-calculated $\mathrm{HCl}$ is released even up to 90 min without any observed organic vapors.

Since the thermal degradation reactions proceed with significant activation energies then the temperature has an important effect on the rate. In the same way, dechlorination of polyvinyl chloride waste at $250{ }^{\circ} \mathrm{C}$ and different period of times was also investigated. There is slight difference in the trend of $\mathrm{HCl}$ evolution. About $30 \%$ of $\mathrm{HCl}$ is emitted in the first stages during $15 \mathrm{~min}$ of heating. Further increase of the heating time led to slow rate of release with the total of about $52 \%$ during 150 min heating time without any observation of organic fumes.

It is very obvious that the emission of $\mathrm{HCl}$ reaches $40 \%$ during only $7.5 \mathrm{~min}, 48 \%$ and $80 \%$ in $15 \mathrm{~min}$ and $60 \mathrm{~min}$ heating time respectively, when the waste was heated at 275 ${ }^{\circ} \mathrm{C}$. Insignificant effect of heating time on release of $\mathrm{HCl}$ was detected when heating time was continued up to $90 \mathrm{~min}$. At $300{ }^{\circ} \mathrm{C}$, the release of $\mathrm{HCl}$ is more effective than $275{ }^{\circ} \mathrm{C}$ degradation temperature by as much as $25 \%$ in the first stages (15 min). In addition, the yellow organic fumes are observed 
after 22 min degradation time.

Fig. 1 also shows the plot of degradation time of PVC waste versus $\% \mathrm{HCl}$ released under nitrogen atmosphere at $325^{\circ} \mathrm{C}$. When the waste heated for $11 \mathrm{~min}$ the percentage of $\mathrm{HCl}$ reaches to about $72 \%$ and yellow organic vapors are observed. The results indicate that the degradation temperature plays an important role in the overall release of hydrogen chloride. Almost complete release of $\mathrm{HCl}$ gas was at $300{ }^{\circ} \mathrm{C}$ and this seems to be the optimum temperature for the removal of chlorine from the PVC waste. The sharp increase in the $\mathrm{HCl}$ release in the first stages for all processing temperatures could be due to the dechlorination of the outer layers of the PVC waste particles resulted from direct contact with heat. Further heating time led to relative slow release. That may be attributed to the formation of thermal crosslinking of the chains which could result in a dense matrix and prevent the dechhlorination process. As a result, high temperature is needed to complete the degradation process and emission of the rest of $\mathrm{HCl}$ and other organic products.

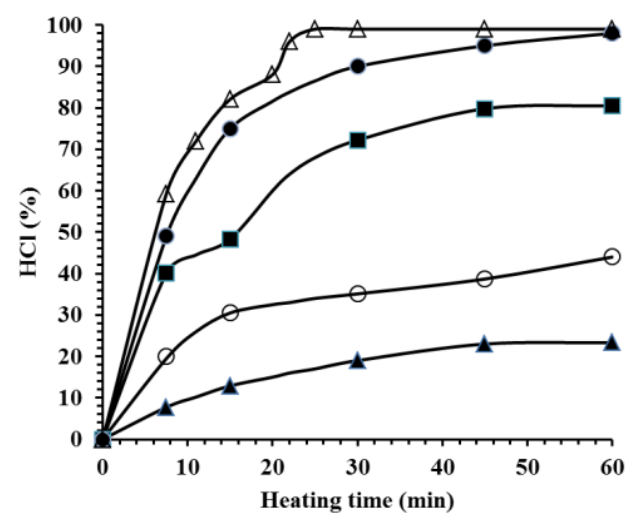

Fig. 1. Effect of degradation time of PVC waste of particle size ranged from 0.5-4 $\mathrm{mm}$ on the release of $\mathrm{HCl}$ at various temperatures $\left[\boldsymbol{\Delta}: 200{ }^{\circ} \mathrm{C}, \mathrm{O}: 250\right.$ $\left.{ }^{\circ} \mathrm{C}, \mathbf{\varpi}: 275^{\circ} \mathrm{C}, \bullet: 300{ }^{\circ} \mathrm{C}, \Delta: 325^{\circ} \mathrm{C}\right]$.

The thermal degradation does not depend on initial amount of polymer but the rate of degradation process may depend on the particle size of the waste. For this reason, the rigid PVC waste samples of different particle sizes $(0.5,1.0$ and $2.0 \mathrm{~mm}$ diameters) are subjected to thermal degradation at $300{ }^{\circ} \mathrm{C}$. Fig. 2 represents the percentage of $\mathrm{HCl}$ released versus heating time at $300{ }^{\circ} \mathrm{C}$ for a particle size of $0.5 \mathrm{~mm}$. It is very clear that most of $\mathrm{HCl}(88 \%)$ was released during 10 min of the degradation process. The organic vapors started to appear at $16.5 \mathrm{~min}$ while about $95 \%$ of $\mathrm{HCl}$ was released.

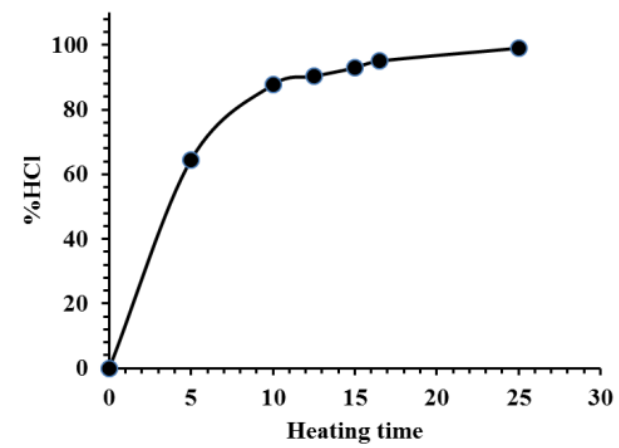

Fig. 2. Effect of degradation time of PVC waste of $0.5 \mathrm{~mm}$ particle size on the release of $\mathrm{HCl}$ at $300{ }^{\circ} \mathrm{C}$.
Table I presents the relationship between the particle sizes, degradation temperature, percentage of hydrogen chloride released and recorded time of starting of yellow organic vapors emission. A significant effect of particle size on both the percentage of $\mathrm{HCl}$ and time of emission of organic vapors are observed. It is noticeable that the smaller the particle sizes the higher the rate of dichlorination and the rapid the formation of organic compounds. That could be attributed to (1) increase of surface areas in contact with heat and (2) disability of small particle to retain the $\mathrm{HCl}$ gas and organics in the last stages of the decomposition.

TABLE I: THE RELATIONSHIP BETWEEN THE PARTICLE SIZES, DEgRAdATION TEMPERATURE, PERCENTAgE OF Hydrogen CHLORIDE RELEASED AND TIME OF STARTED YELLOW ORGANIC VAPORS EMISSION

\begin{tabular}{||c||c||c|c||}
\hline $\begin{array}{c}\text { Particle size } \\
(\mathrm{mm})\end{array}$ & $\begin{array}{c}\text { Heating } \\
\text { temperature }\left({ }^{\circ} \mathrm{C}\right)\end{array}$ & $\begin{array}{c}\mathrm{HCl} \\
(\%)\end{array}$ & $\begin{array}{c}\text { Time of organics } \\
\text { evolved }(\mathrm{min})\end{array}$ \\
\hline 0.5 & 300 & 95 & 16.5 \\
\hline \hline 1.0 & 300 & 93.20 & 18.0 \\
\hline \hline 2.0 & 300 & 92.00 & 21.0 \\
\hline \hline $0.5-4.0$ & 300 & 90.00 & 22.0 \\
\hline $0.5-4.0$ & 325 & 71.99 & 11.0 \\
\hline \hline
\end{tabular}

Fig. 3 presents the obtained concentration of $\mathrm{HCl}$ solution resulted from the thermal degradation of PVC waste in both traps at $300{ }^{\circ} \mathrm{C}$ and 16 min heating time. It is very clear that most of the emitted $\mathrm{HCl}$ was collected in the first trap due to the very high solubility of the gas in distilled water forming highly concentrated hydrochloric acid solution. The maximum concentration of $\mathrm{HCl}$ solution obtained under these experimental conditions was $11.2 \mathrm{M}$ which is nearly the same as the concentration of commercial laboratory grade hydrochloric acid. Generally, the weight of both the released $\mathrm{HCl}$ and the residual material from the thermal degradation represent most of the original weight of the PVC samples. To investigate the purity of the achieved acid solution, sodium chloride salt was prepared and analyzed by CHNS. The results showed that the concentration of carbon and hydrogen were under the detection limit of the instrument. It revealed that the hydrochloric acid is free of any organics.

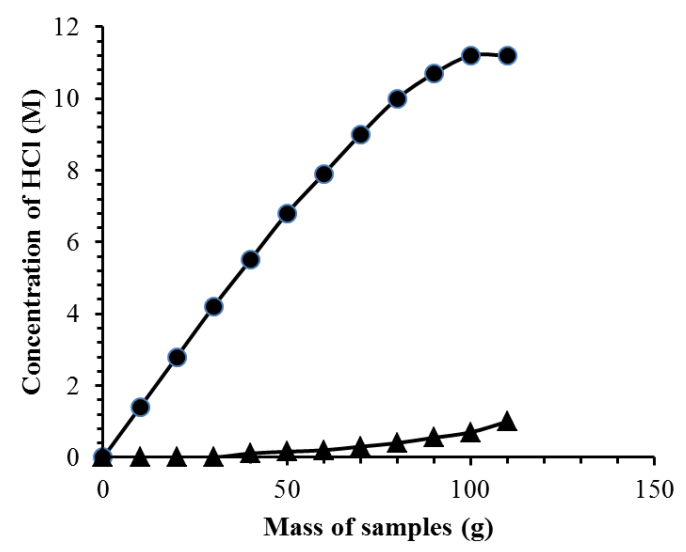

Fig. 3. Molar concentration of the collected hydrochloric acid [ $\bullet$ : first trap, $\boldsymbol{\Delta}$ : second trap].

The residual materials from the previous experiments are subjected to higher temperature to complete its thermal degradation in order to be converted to organic compounds 
and carbon black powder. The percentage of the obtained carbon powder was about $27 \%$ of the PVC waste. The concentration of the extractable heavy metals in carbon powder, virgin PVC as a reference sample and organics were analyzed and the data is presented in Table II. Available $\mathrm{Pb}$ has the highest concentration in the produced carbon black from PVC waste and unavailable in both virgin PVC and organics. The presence of high concentration of $\mathrm{Pb}$ in the carbon powder ( $\left.37.43 \mathrm{mg} . \mathrm{g}^{-1}\right)$ was due to the addition of lead organic compounds as additives during the PVC processing. The small concentration of $\mathrm{Zn}$ and $\mathrm{Fe}$ in carbon powder and virgin PVC may be due to contact of PVC with metal surfaces of equipment during production and processing steps. The concentrations of heavy elements in organic compounds were under the detection limit. In addition, about $14 \%$ of initial weight was found to be as heavy metals free oil and that could be used as fuel.

TABLE II: CONCENTRATION OF HEAVY METALS IN CARBON BLACK POWDER AND ORGANIC COMPOUNDS

\begin{tabular}{|c||c||c|c||}
\hline Metal & $\begin{array}{c}\text { Black Carbon } \\
\left(\mathrm{mg}^{-1}\right)^{-1}\end{array}$ & $\begin{array}{c}\text { Virgin PVC } \\
\left(\mathrm{mg.g}^{-1}\right)\end{array}$ & $\begin{array}{c}\text { Organic } \\
\text { Compounds } \\
\left(\mathrm{mg}^{-1} \mathrm{~g}^{-1}\right)\end{array}$ \\
\hline $\mathrm{Pb}$ & 37.43 & $*$ & $*$ \\
\hline $\mathrm{Zn}$ & $34.08 \times 10^{-3}$ & $1.69 \times 10^{-3}$ & $*$ \\
\hline $\mathrm{Fe}$ & 0.42 & $10.20 \times 10^{-3}$ & $*$ \\
\hline $\mathrm{Cd}$ & $*$ & $*$ & $*$ \\
\hline $\mathrm{Cu}$ & $*$ & $*$ & $*$ \\
\hline $\mathrm{Co}$ & $*$ & $*$ & $*$ \\
\hline
\end{tabular}

*: Under Detection Limit.

\section{CONCLUSION}

The study of PVC waste degradation under controlled inert conditions revealed that the dehydrochlorination was dependent on temperature, heating time and grain size. It was increased with raising temperature and the optimum dehydrochlorination temperature was $300{ }^{\circ} \mathrm{C}$. Furthermore, the rate dechlorination and $\mathrm{HCl}$ formation was increased with heating time but decreased when particle size increased. The highest percentage of $\mathrm{HCl}(95 \%)$ liberated when the sample of $0.5 \mathrm{~mm}$ grain size was heated at $300{ }^{\circ} \mathrm{C}$ for $16 \mathrm{~min}$ before any observation of yellow organic fumes. The maximum concentration of hydrochloric acid solution prepared from this experiment was $11.22 \mathrm{M}$ without any detected hydrocarbon or heavy metals contamination.

\section{REFERENCES}

[1] V. Misra and S. D. Pandey, "Hazardous waste, impact on health and environment for development of better waste management strategies in future in India," Environmental International, vol. 31, pp. 417-431, April 2005.

[2] M. Sadat-Shojai and G. R. Bakhshandeh, "Recycling of PVC wastes," Polymer Degradation and Stability, vol. 96, no. 4, pp. 404-415, April 2011.
[3] D. Braun, "Recycling of PVC," Progress in Polymer Science, vol. 27, pp. 2171-2195, December 2002.

[4] S. Kim, "Pyrolysis kinetics of waste PVC pipe," Waste Management, vol. 21, no. 7, pp. 609-616, August 2001

[5] R. Miranda, J. Yang, C. Roy, and C. Vasile. "Vacuum pyrolysis of PVC I. Kinetic study," Polymer Degradation and Stability, vol. 64, pp. 127-144, January 1999.

[6] H. M. Zhu, X. G. Jiang, J. H. Yan, Y. Chi, and K.F. Cen, "TG-FTIR analysis of PVC thermal degradation and $\mathrm{HCl}$ removal," J. Analyl \& Appl. Pyrolysis vol. 82, pp. 1-9, May 2008.

[7] J.-L. Wu, T.-J. Chen, X.-T. Luo et al., "TG/FTIR analysis on co-pyrolysis behavior of PE, PVC and PS," Waste Management, vol. 43, pp. 676-682, March 20014.

[8] C. Alexandra, S. Delfim, V. Cândida, and C. Fer-nando, "Kinetics of thermal de-chlorination of PVC under pyrolytic conditions," Waste Management, vol. 32, pp. 847-851, May 2002.

[9] S. Loay, T. Antti, H. Matti, and Z. Ron, "Slow pyrolysis of different PVC types in a bubbling fluidized bed: stabilizer effects," J. Analy. \& Appl. Pyrolysis, vol. 72, pp. 63-74, August 2004.

[10] S. Ma, J. Lu, and J. Gao, "Study of the low temperature pyrolysis of PVC," Energy \& Fuels, vol. 16, pp. 338-342, March 2002.

[11] Z. He, W. Xiao et al., "Thermogravimetric-mass spectrometric study of the pyrolysis behavior of PVC," J. China University of Mining \& Technology, vol. 17, pp. 242-245, June 2007.

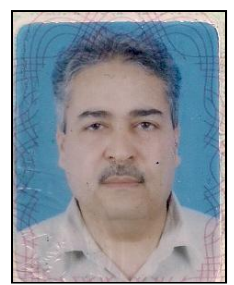

Abduel Majid K. Najjar was born in Tripoli, Libya He was awarded the Ph.D. degree from the University Putra Malaysia (UPM), Malaysia in 2002 in the field of polymer chemistry. He worked for Tajoura Research Center at Chemistry Department for 10 years and for Center for Macromolecular Chemistry \& Technology, Tripoli-Libya for 9 years as a research staff

Now he is an associate professor at the Department of Chemical Engineering, Faculty of Engineering (Algaraboli), Almergib University, Libya.

Dr. Abduel Majid research areas related to polymer chemistry (polymers syntheses, characterization and applications) and environmental science.

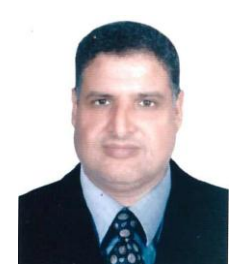

Mohamed A. Elmelah (Almallah) was awarded the Ph.D. degree in chemistry in 1984 from the Chemistry Department of New Mexico State University (NMSU), NM, USA. Since then he has been a member of the Chemistry Staff at the University of Tripoli in the Faculty of Science. During these years he has been the head of the Department, dean of Faculty of Science and head of the organizing committee of the "First Environmental Conference" and a member of the "First Basic Sciences Conference" held in Libya. He has a membership in the "American Chemical Society" and the "Libyan Chemical Society".

Currently, professor Mohamed holds the position of a professor in the Chemistry Department at the University of Tripoli, Libya. His research interest include environmental and coordination chemistry.

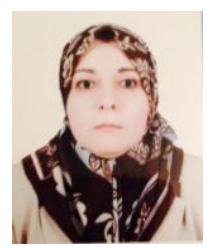

Fahima N. Abudher got the B.Sc. degree from the Chemistry Department, Faculty of Science, Tripoli University. She has worked as a laboratory technician at the Department of Chemistry. She is working also as a research assistant with research group.

Currently, Fahima is interesting in environmental and organic chemistry research.

Rashid S. R. Ltayef has obtained his M.Sc. degree from the Department of Environmental Science and Engineering, Libya Academy of Higher Studies, Tripoli, Libya. He is working as a lecturer at Higher Institute. 